\title{
FACTORS CONTRIBUTING TO SELF-REPORTED CELL PHONE USAGE BY YOUNGER DRIVERS IN THE PACIFIC NORTHWEST
}

\author{
Hisham Jashami, Masoud Ghodrat Abadi, and David S. Hurwitz \\ Transportation Engineering, Oregon State University \\ Corvallis, Oregon, USA \\ Email: david.hurwitz@oregonstate.edu
}

\begin{abstract}
Summary: Using a cell phone while driving has been shown to have a negative impact on driver performance. To determine why younger drivers persist in using cell phones while driving, underlying causal factors which contribute to selfreported usage were investigated. A total of 2,340 drivers, from high schools and universities located in Alaska, Idaho, Oregon, and Washington responded to a survey instrument. Drivers were asked to self-report their frequency of distraction and their opinion about what activities are driving distractions. The objective was to determine what factors impact the driver choice to interact with a cell phone (talking or texting) while driving. A random parameter ordered-probit model was developed to predict the likelihood that a driver self-reported cell phone activity while driving as "infrequent", "moderate", or "frequent". It was found that the behaviors of texting and talking while driving were highly correlated. The developed models suggest that presence of friends in the car, parents frequently exhibiting distracted driving, more miles of driving, history of speeding tickets, crash history, having a full driver's license, owning an iPhone, and being female increases the likelihood of self-reported distracted driving. It was found that experienced drivers were more likely to talk and less likely to text while driving.
\end{abstract}

\section{INTRODUCTION}

Cell phones have increasingly become a significant part of everyday life. Cell phone ownership among American adults and teens dramatically increased between 2005 and 2015 from 65\% to $92 \%$ for adults, and from $45 \%$ to $73 \%$, for teens (NHTSA, 2015). These statistics suggest at least the possibility of increased cell phone use while driving. Using cell phones while driving has a proven negative impact on driver performance (Regan et al., 2008).

There are many activities that can result in manual, visual, and cognitive distraction while driving. Each can negatively impact drivers in terms of their ability to maintain lane position, speed, and eyes on the road (Harbluk et al., 2007). Cell phone use has been identified as a driving distraction and increases the likelihood of crash involvement (NHTSA, 2015). Numerous research efforts have focused on the hazards associated with distracted driving (e.g.Westlake and Boyle, 2007).

Texting while driving is a more significant distraction than talking on the phone as the behavior combines manual, visual, and cognitive components of distraction (Libby and Chaparro, 2009). Libby and Chaparro used a STISIM version 8 simulator to evaluate 34 participants' driving performance while talking or texting (2009). They found that texting was more dangerous than 
talking as drivers drove more slowly while texting, took their eyes off the road more frequently, and demonstrated worse lateral control.

Talking on a hand-held and hands-free phone while driving have the same crash-risk involvement (e.g., McEvoy et al., 2005; Strayer et al., 2006). Both studies emphasized that simply talking on the phone while driving is associated with an approximate fourfold increased risk of a crash. McEvoy et al. (2005) gave a proximate factor of risk from approximately 3.8 for hands-free to 5.6 for hand-held cell phone conversations. Additionally, they found that talking on the phone increases reaction time and the frequency of lane changes, and decreases the maintenance of speeds and following distances (Collet et al., 2010).

Although drivers support laws banning cell phone use while driving, naturalistic data has shown that distractions are pervasive in everyday driving, thus degrading driver performance (Stutts et al., 2005). To examine why cell phone use while driving persists, underlying causal factors which contribute to self-reported usage need to be carefully addressed. The motivations behind this behavior may be highly influenced by different factors. Therefore, the objective of this study was to answer the following three research questions:

- How are self-reported distracted driving activities (e.g. texting and talking) related?

- What factors increase the likelihood of self-reported texting while driving?

- What factors increase the likelihood of self-reported talking on cell phone while driving?

To address this goal, random parameter ordered-probit models were developed to examine those factors. Few previous studies have focused on evaluating factors impacting drivers' mobile phone use (e.g., Engelberg et al., 2015). These evaluations were primarily based on descriptive statistics (e.g., Emanuel, 2013), probabilistic techniques (e.g., Engelberg et al., 2015), or small sample sizes (e.g., Libby and Chaparro, 2009). The current study investigated driving behavior of two cohorts (high school and college students) with an econometric method to account for the heterogeneity of factors that influence the behavior of individuals to choose a specific level of distraction relative to a particular activity.

\section{METHOD}

\section{Data Sources}

In 2015, five different universities (Oregon State University, University Of Washington, University Of Idaho, University Of Alaska Anchorage, and Washington State University) designed a pre- and post-demonstration survey regarding the dangers of distracted driving in the Pacific Northwest region. At five high schools and five universities (Figure 1), approximately 2,500 participants took part in the interactive demonstrations, and 2,377 returned the survey (a response rate of 95\%): 1,008 were high school students and 1,369 were university students.

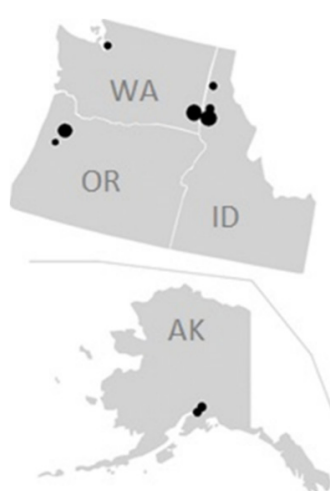

Figure 1. Data collection sites in the Pacific Northwest 
The pre- and post-surveys asked students to rate (on a seven point rating scale) how distracting they perceived specific activities to be while driving. Data on general demographics such as gender, year in school, age, etc. and information on driving habits was collected through a series of self-reported questions. Additionally, the pre-survey asked more specific questions about driving history and experience, license type and training, driving frequency and duration, and how often and when they and/or their parent engage in specific secondary tasks. The pre-survey consisted of 27 questions and took approximately 10-15 minutes to complete, while the postsurvey had 13 questions and took approximately 5-10 minutes (Hurwitz et al., 2015).

Since this study is focused on the use of cell phones while driving, which was well represented in the survey, 21 questions (from five different parts) were chosen for conducting the analysis. Part one measured the self-reported level of involvement in secondary tasks, which was used as the dependent variable in our analysis. Students were asked to report how often they talk on a mobile (cell) phone or text a message while driving (not while stopped). Responses were given on a seven-point rating scale, which were aggregated and classified as a group of three categorical dependent variables " $0=$ INFREQUENT", " $1=$ MODERATE", and " $2=$ FREQUENT". The ordinal nature of the data lent itself to analysis with an ordered-probit model. Part 2-5 (distractions, typical drive characteristics, drivers' license, and about participant demographics) were all independent variables and are presented in Table 1. Participants were $57.46 \%(\mathrm{n}=1308)$ male and $42.58 \%(n=970)$ female (mean age $=19.75, \mathrm{SD}=4.64)$.

Table 1. Variable definition and descriptive statistics

\begin{tabular}{|c|c|c|c|}
\hline Variable & Description & Mean & SD \\
\hline TEXT & $\begin{array}{c}\text { Frequency of texting while driving } \\
(0=\text { Infrequent, } 1=\text { Moderate, } 2=\text { Frequent })\end{array}$ & 0.536 & 0.800 \\
\hline TALK & $\begin{array}{l}\text { Frequency of talking on the phone while driving } \\
(0=\text { Infrequent, } 1=\text { Moderate, } 2=\text { Frequent })\end{array}$ & 0.556 & 0.729 \\
\hline FRND & Usual passengers $(1=$ Friends, $0=$ Otherwise $)$ & 0.608 & 0.488 \\
\hline PRNT & Parents doing distracted driving ( $1=$ frequent, $0=$ otherwise $)$ & 0.496 & 0.500 \\
\hline MILE & Number of miles (in hundreds) driven during last week & 0.791 & 1.675 \\
\hline TCKT & Receive speeding ticket $(1=$ Yes, $0=$ No $)$ & 0.282 & 0.450 \\
\hline EXPR & Years of holding driver's license & 3.943 & 4.656 \\
\hline CRSH & Involvement in a crash $(1=$ Yes, $0=$ No $)$ & 0.363 & 0.481 \\
\hline LCNS & Type of driver's license $(1=$ Full License, $0=$ Otherwise $)$ & 0.636 & 0.481 \\
\hline IPHN & Type of cellphone ( $1=$ iPhone, $0=$ Otherwise $)$ & 0.621 & 0.485 \\
\hline GNDR & Gender $(1=$ Male, $0=$ Female $)$ & 0.575 & 0.494 \\
\hline
\end{tabular}

\section{ANALYSIS}

To investigate the relationship between texting and talking on a cell phone while driving, a heat map of the interaction of the two dependent variables (Figure 2) and the number of observations in each category (Table 2) are presented. As can be seen, the highest density of responses were categorized as infrequent texting and talking while driving (48.89\% of all the responses). The interaction of texting and talking was further analyzed using polychoric correlation and it was found that there is a strong correlation between these two variables $(r=0.630, p<0.001)$. 


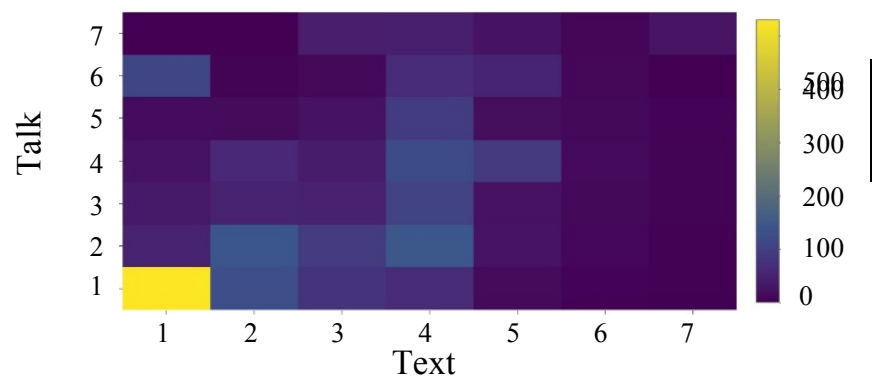

Figure 2. Interaction of Texting and Talking

\begin{tabular}{|c|c|c|c|}
\hline \multirow{5}{*}{$\begin{array}{l}\text { Frequent } \\
\text { Moderate } \\
\text { Infrequent }\end{array}$} & 87 & 103 & 146 \\
\hline & 312 & 121 & 203 \\
\hline & 1144 & 120 & 104 \\
\hline & Infrequent & Moderate & Frequent \\
\hline & \multicolumn{3}{|c|}{ Text } \\
\hline
\end{tabular}

Table 2. Number of observations in each category

To better understand the factors associated with underlying causal factors which contribute to self-reported usage of cell phone while driving, a random parameters ordered-probit modeling approach was developed to determine the probability that a participant self-reported a specific level. This probability was coded as infrequent (0), moderate (1), or frequent (2) engagers. Since the level of engagement is ordinal in nature, and to account for potential observed and unobserved heterogeneities in the data, this approach was carefully selected. If random was not suggested for the distribution of dependent variables, unobserved heterogeneity due to driver behavior can lead to overestimating the coefficients (Chistoforou et al., 2010). Accordingly, the influence of variables affecting participant level of engagement may vary. A random parameters ordered-probit model accounts for these variations and is formulated as follows:

$p_{n}(y=1)=1-\Phi\left(\mu_{I-1}-\beta X\right)$

where $p_{n}(y=1)$ is the probability of observation $n$ has I as the highest ordered response index (e.g., for frequent texting engagement level, this is $2, \Phi(\cdot)$ is a standard normal cumulative function, $\mu$ is estimable parameter that define $y$ and is estimated jointly with the model parameters $\beta, X$ is a vector of explanatory variables, and $\beta$ is a vector of estimable parameters (Washington et al., 2011).

Separate models were developed to determine the self-reported responses for both texting and talking secondary tasks. The entire dataset (2,378 responses) was used to model the responses. After removing missing data, the original dataset was reduced to 2,340 observations. A backward stepwise procedure was used to select significant and exclude insignificant variables from the final models. Table 1 presents the definitions and descriptive statistics (means and standard deviations SDs) for the final variables in the models. The correlation matrix for the ordered-probit model was tested and showed that all variables were less than 0.4 (absolute value).

Econometric software NLOGIT3 was used to develop the models. Random parameters were obtained from 200 random draws using standard Halton sequence intelligent draws (Halton, 1960). Considering normal, triangular, and uniform distributions, random parameters were tested to check for the best distribution. Normal distributions resulted in the best statistical fits. Table 3 shows results of the random parameter ordered-probit model estimates of participant responses to level of involvement. In either model, random parameters were those that produced statistically significant standard errors for their assumed distribution. All estimated parameters included in the models were statistically significant, and all of the signs were plausible. 
Table 3. Analysis of participant responses to level of engagement

\begin{tabular}{|c|c|c|c|c|c|c|c|c|c|c|}
\hline \multirow{3}{*}{ Variable } & \multicolumn{5}{|c|}{ TEXT } & \multicolumn{5}{|c|}{ TALK } \\
\hline & \multirow{2}{*}{$\begin{array}{l}\text { Coef. } \\
\text { (SD) }\end{array}$} & \multirow{2}{*}{ t-Stat } & \multicolumn{3}{|c|}{ Marginal Effects } & \multirow{2}{*}{$\begin{array}{l}\text { Coef. } \\
\text { (SD) }\end{array}$} & \multirow{2}{*}{ t-Stat } & \multicolumn{3}{|c|}{ Marginal Effects } \\
\hline & & & $\mathrm{Y}=0$ & $\mathrm{Y}=1$ & $\mathrm{Y}=2$ & & & $\mathrm{Y}=0$ & $\mathrm{Y}=1$ & $\mathrm{Y}=2$ \\
\hline Constant & -1.460 & -20.170 & 0.000 & 0.000 & 0.000 & -1.219 & -19.431 & 0.000 & 0.000 & 0.000 \\
\hline FRND & 0.469 & 8.892 & -0.152 & 0.078 & 0.074 & 0.523 & 12.120 & -0.202 & 0.104 & 0.098 \\
\hline PRNT & 0.248 & 5.172 & -0.083 & 0.042 & 0.042 & 0.175 & 4.436 & -0.069 & 0.034 & 0.034 \\
\hline MILE & 0.043 & 3.619 & -0.015 & 0.007 & 0.007 & 0.043 & 4.245 & -0.017 & 0.008 & 0.009 \\
\hline TCKT & 0.839 & 14.618 & -0.299 & 0.125 & 0.174 & 0.260 & 5.740 & -0.103 & 0.048 & 0.055 \\
\hline EXPR & -0.034 & -5.032 & 0.012 & -0.006 & -0.006 & $\begin{array}{c}0.031 \\
(0.043)\end{array}$ & 10.648 & -0.012 & 0.006 & 0.006 \\
\hline CRSH & 0.115 & 2.330 & -0.039 & 0.019 & 0.020 & - & - & - & - & - \\
\hline LCNS & $\begin{array}{c}0.464 \\
(0.058)\end{array}$ & 1.886 & -0.145 & 0.077 & 0.067 & 0.623 & 11.920 & -0.233 & 0.129 & 0.104 \\
\hline IPHN & $\begin{array}{c}0.043 \\
(0.763)\end{array}$ & 23.425 & -0.014 & 0.007 & 0.007 & $\begin{array}{c}0.037 \\
(0.353)\end{array}$ & 11.644 & -0.015 & 0.007 & 0.007 \\
\hline GNDR & $\begin{array}{c}-0.164 \\
(1.068)\end{array}$ & 19.302 & 0.056 & -0.027 & -0.028 & -0.127 & -3.126 & 0.050 & -0.024 & -0.026 \\
\hline \multicolumn{4}{|c|}{ Number of observations } & \multicolumn{2}{|c|}{2340} & \multicolumn{5}{|c|}{2340} \\
\hline \multicolumn{4}{|c|}{ Threshold 1, $\mu 1$} & \multicolumn{2}{|c|}{$0.731(26.797)$} & \multicolumn{5}{|c|}{$1.017(38.937)$} \\
\hline \multicolumn{4}{|c|}{ Log likelihood at convergence } & \multicolumn{2}{|c|}{-1114.013} & \multicolumn{5}{|c|}{-1223.389} \\
\hline \multicolumn{4}{|c|}{ Restricted log likelihood } & \multicolumn{2}{|c|}{-1199.394} & \multicolumn{5}{|c|}{-1330.625} \\
\hline
\end{tabular}

All of the common variables between the two models had similar signs except the variable EXPR which represents the driver's level of experience. In other words, except for experience, each variable that increased the probability of texting also increased the probability of talking over the phone.

As fixed (non-random) parameters, it was found that presence of friends as usual passengers (FRND), having parents who are frequently distracted while driving (PRNT), more miles of driving (MILE), and recipients of speeding tickets (TCKT) increased the self-reported probability of both texting and talking on phone while driving. According to the marginal effects, among all fixed parameters, the independent variables TCKT and FRND had the highest impact on self-reported texting and talking. Developed models showed that if a driver had ever received a speeding ticket, the self-reported probability of frequent texting while driving by that person increased by $17.4 \%$, and the self-reported probability of moderate or frequent talking on cell phone increased by $10.3 \%$. Similarly, the presence of friends as usual passengers in the vehicle increased the probability that a driver self-reported frequently texting or talking on a phone by $7.4 \%$ and $9.8 \%$, respectively. Involvement in a crash $(\mathrm{CRSH})$ had a statistically significant relationship with texting while driving. Drivers who had been involved in a crash were more likely to self-report texting while driving by $4 \%$. CRSH was not statistically significant in talking on a phone so it was removed from further analysis. 
Having a full driver's license (LCNS), owning an iPhone (IPHN), and being a female (GNDR) were also found to increase the self-reported probability of texting or talking on the phone while driving. In response to texting, LCNS was a normally distributed (random) parameter with a mean of 0.46 and SD of 0.06 . For approximately $99 \%$ of cases, LCNS increased the likelihood of self-reporting frequent texting. GNDR was also a normally distributed (random) parameter with a mean of -0.16 and SD of 1.07 . For approximately $55 \%$ of cases, being male decreased the likelihood of frequent texting. IPHN was a random parameter for both activities. Owning an iPhone was a normally distributed variable (mean $=0.04$; $\mathrm{SD}=0.76$ ) for texting, and with a mean of 0.04 and SD of 0.35 for talking. For approximately $52 \%$ of texting and $53 \%$ of talking respondents, owning an iPhone increased the probability of using a cell phone while driving.

In response to talking on the phone, years of licensure (EXPR) was a normally distributed (random) variable with a mean of 0.03 and SD of 0.04 . For approximately $72 \%$ of cases, greater driving experience increased probability of self-reported frequent talking. When modeling texting, EXPR was a fixed parameter that decreased the probability of frequent text engagement.

\section{SUMMARY AND CONCLUSION}

This study employed general demographic information and specific driving behaviors of young drivers in the Pacific Northwest to evaluate the underlying factors which contribute to selfreported usage of cell phone (texting and talking) while driving. It was found that these distracted activities are highly correlated, such that people who tend to self-report infrequently/frequently text while driving are also self-report infrequently/frequently involved with talking on the phone. A significant limitation of the study is that perceptions are not actions, and it is unclear how self-reported perceptions translate to real world behavior even though strong correlations were observed.

Modeling the characteristics of self-reported distraction by younger drivers revealed interesting findings. The presence of friends in the vehicle, driving more miles, having a full driving license, and owning an iPhone increased the probability of using cell phone while driving. It was also concluded that the driving behavior of younger participants is considerably influenced by their parents, as regular distracted driving by parents increased the probability of distracted driving by their children. In this study, having received a speeding ticket was considered a proxy of driver's tendency to violate traffic laws. It was found that using a cell phone, either for texting or talking, is more likely among people who disregard general traffic laws (e.g., speed limit). Similarly, being involved in a crash was considered a proxy of reckless driving. It was found that people with a crash history are still more likely to text while driving. Gender was another variable to play a role in distracted driving as it was found that female participants were more likely to use their cell phone, either to text or talk, while driving. Finally, the experience of drivers was found to be important in the type of secondary tasks performed while driving. It was found that experienced drivers are more likely to talk and less likely to text while driving.

\section{ACKNOWLEDGMENTS}

This material is based in part upon work supported by the Pacific Northwest Transportation Consortium (PacTrans). Any opinions, findings, and conclusions or recommendations expressed in this material are those of the author(s) and do not necessarily reflect the views of PacTrans. 


\section{REFERENCES}

Chistoforou, Z., Cohen, S., and Karlaftis, M. G. (2010). "Vehicle occupant injury severity on highways: An empirical investigation.” Accid. Anal. Prev., 42(6), $1606-1620$.

Collet, C., Guillot, A., Petit, C., 2010. Phone while driving I: a review of epidemio-logical, psychological, behavioral and physiological studies. Ergonomics 53 (5), 589-601.

Engelberg, J. K., Hill, L. L., Rybar, J., \& Styer, T. (2015). Distracted driving behaviors related to cell phone use among middle-aged adults. Journal of Transport \& Health, 2(3), 434-440.

Halton, J. (1960). "On the efficiency of certain quasi-random sequences of points in evaluating multi-dimensional integrals." Numerische Mathematik, 2(1), 84-90.

Harbluk, J. L., Noy, Y. I., Trbovich, P. L., \& Eizenman, M. (2007). An on-road assessment of cognitive distraction: Impacts on drivers' visual behavior and braking performance. Accident Analysis \& Prevention, 39(2), 372-379.

Hurwitz, D. S., Boyle, L., Abdel-Rahim, A., Bham, G., \& Cofer, W. (2015) Educating younger drivers in the Pacific Northwest regarding the dangers of distracted driving (Phase II). Pacific Northwest Transportation Consortium (PACTRANS), 2013-M-OSU-0028, 29.

Libby, D., \& Chaparro, A. (2009, October). Text messaging versus talking on a cell phone: a comparison of their effects on driving performance. In Proceedings of the Human Factors and Ergonomics Society Annual Meeting(Vol. 53, No. 18, pp. 1353-1357). Sage Publications.

McEvoy, S.P., Stevenson, M.R., McCartt, A.T.,Woodward, M., Haworth, C., Palamara, P., Cercarelli, R., 2005. Role of mobile phones in motor vehicle crashes resulting in hospital attendance: a case-crossover study. BMJ 331 (7514), 428.

NHTSA, 2015. What is Distracted Driving? Facts and Statistics. Available from: http://www.distraction.gov/stats-research-laws/facts-and-statistics.html. (Accessed 10.26.2016).

Strayer, D. L., Drews, F. A., \& Crouch, D. J. (2006). A comparison of the cell phone driver and the drunk driver. Human factors: The journal of the human factors and ergonomics society, 48(2), 381-391.

Stutts, J., Feaganes, J., Reinfurt, D., Rodgman, E., Hamlett, C., Gish, K., et al (2005). Driver's exposure to distractions in their natural driving environment. Accident Analysis and Prevention, 37(6), 1093-1101.

Washington, S. P., Karlaftis, M. G., and Mannering, F. L. (2011). Statistical and econometric methods for transportation data analysis, 2nd Ed., Chapman and Hall/CRC, Boca Raton, FL.

Westlake, E. J., \& Boyle, L. N. (2012). Perceptions of driver distraction among teenage drivers. Transportation research part F: traffic psychology and behaviour, 15(6), 644653.

Young, K., Lee, J. D., \& Regan, M. A. (Eds.). (2008). Driver distraction: Theory, effects, and mitigation. CRC Press.

Emanuel, R. C. (2013). The American college student cell phone survey. College Student Journal, 47(1), 75. 